\title{
PENGARUH PEMERIKSAAN KEHAMILAN SECARA TERATUR TERHADAP KEJADIAN PREEKLAMSI
}

\author{
Tutik Ekasari ${ }^{1)}$, Mega Silvian Natalia ${ }^{2)}$ \\ Program Studi Diploma Kebidanan, STIKes Hafshawaty Pesantren Zainul Hasan \\ e-mail: ekasari372011@gmail.com
}

\begin{abstract}
ABSTRAK
Kematian ibu tertinggi disebabkan oleh Preeklamsi. Kejadian preeklamsia dapat dikatakan sebagai masalah kesehatan masyarakat jika CaseFatalityRate (CFR) preeklamsia mencapai 1,4\% - 1,8\%.Menurut data terakhir prevalensi kejadian preeklamsia di Indonesia sekitar 3-10\%. Angka tersebut menunjukkan bahwa kejadian preeklamsia di Indonesia melewati batas CFR sehingga preeklamsia menjadi salah satu masalah kesehatan masyarakat. Angka Kematian Ibu (AKI) pada tahun 2017 di Kabupaten Probolinggo sebanyak 14 orang. Penyebab langsung kematian ibu pada tahun 2017 disebabkan karena Perdarahan (15\%), Preeklamsi/Eklamsi (50\%), Infeksi (5\%), Emboli Air Ketuban (5\%), dan Lain-lain(25\%). Semakin meningkatnya kejadian preeklampsi di Kabupaten Probolinggo diduga karena ibu hamil tidak memeriksakan kehamilannya secara teratur. Penelitian ini bertujuan menganalisis pengaruh pemeriksaan kehamilan secara teratur terhadap kejadian preeklamsia.Desain yang digunakananalitik korelasional dengan pendekatan Retrospektifstudy. Populasi yang digunakan semua ibu hamil pada tahun 2018. Teknik pengambilan sampel dengan purposive sampling dan diperoleh sampel sejumlah 200 orang yang memenuhi kriteria inklusi.Pengumpulan data menggunakan kuesioner dan wawancara. Uji statistik yang digunakan adalah Chi Square. Hasil penelitian menunjukkan bahwa terdapat $50 \%$ ibu hamil yang mengalami preeklamsi, sedangkan 59\% dari ibu hamil yang mengalami preeklamsi tidak memeriksakan kehamilannya secara teratur. Setelah dianalisis dengan Chi Square didapatkan p value 0,003 yang artinya ada pengaruh pemeriksaan kehamilan secara teratur terhadap kejadian preeklamsi.
\end{abstract}

Kata kunci : pemeriksaan kehamilan, teratur, preeklamsi

\begin{abstract}
The highest maternal mortality is caused Preeclampsia. The incidence of preeclampsia can be said to be a public health problem if the Case Fatality Rate (CFR) of preeclampsi areaches $1.4 \%-1.8 \%$. According to the latest data, the prevalence of preeclampsiain Indonesia is around 3-10\%. This figures hows that the incidence of preeclampsiain Indonesia exceeds the CFR limit so that preeclampsia is one of the public health problems. The maternal mortality rate (AKI) in 2017 in Probolinggo Districtis 14 people. The direct cause of maternal deathin 2017 is caused by bleeding (15\%), preeclampsia / eclampsia (50\%), infection (5\%), amnioticembolism (5\%), and others (25\%). The increasing incidence of preeclampsiain Probolinggo Regency is suspected because pregnant women do not check their pregnancy regularly. This study aims to analyze the effect of regular pregnancy examinations on the incidence of preeclampsia. The design used correlational analytic with a retrospective study approach. The population used was all pregnant women in 2018. The sampling technique was purposive sampling and a sample of 200 people met the inclusion criteria. Data collection used questionnaires and interviews. The statistical test used is Chi Square. The results showed that there were 50\% of pregnant women who experienced preeclampsia, while 59\% of pregnant women who experienced preeclampsia did not check their pregnancy regularly. After being analyzed with Chi Square, it was obtained p value 0.003, which means that the reisan effect of regula rpregnancy examinations on the incidence of preeclampsia.
\end{abstract}

Keywords: pregnancy checkup, regular, preeclampsia 


\section{LATAR BELAKANG}

Indikator derajat kesehatan dan kesejahteraan masyarakat, salah satunya dapat dilihat dari AKI maupun AKB (Angka Kematian Bayi). Penyebab klasik kematian ibu di samping infeksi $(15 \%)$ dan preeklamsia $(12 \%)$ adalah perdarahan $(25 \%)$, terutama perdarahan pascapersalinan. Preeklamsia merupakan penyebab $15-20 \%$ kematian ibu. Selain itu preeklamsia juga dapat menjadi penyebab kematian janin (Raghupathy, 2013). Kejadian preeklamsia dapat dikatakan sebagai masalah kesehatan masyarakat jika CaseFatalityRate (CFR) preeklamsia mencapai $1,4 \%$ - 1,8\%. Menurut data terakhir Survei Demografi Kesehatan Indonesia (2012) prevalensi kejadian preeklamsia di Indonesia sekitar 3-10\%. Angka tersebut menunjukkan bahwa kejadian preeklamsia di Indonesia melewati batas CFR sehingga preeklamsia menjadi salah satu masalah kesehatan masyarakat. Dan saat ini belum diketahui pasti penyebab terjadinya preeklamsi (Sumiati, 2012).Gambaran klinik dari masing-masing individu berbeda. Manifestasi klinik yang paling penting sebagai tanda dari preeklamsi adalah proteinuria, hipertensi dan edema. Secara teoritik, urutan gejala tersebut adalah edema, hipertensi dan proteinuria (Nurulia, 2015).

Data yang diperoleh dari Dinas Kesehatan Kabupaten Probolinggo, Angka Kemtian Ibu yang disebabkan oleh preeklamsia pada tahun 2014 yaitu $16,66 \%$, pada tahun 2015 sebanyak $30,77 \%$ dan pada tahun 2016 sebanyak 66,66\%. Angka Kematian Ibu pada tahun 2017 di Kabupaten Probolinggo sebanyak 14 orang. Penyebab langsung kematian ibu pada tahun 2017 disebabkan karena Perdarahan (15\%), Preeklamsi/Eklamsi (50\%), Infeksi (5\%), Emboli Air Ketuban (5\%), dan lain-lain(25\%). Dilihat dari data kematian ibu akibatpreeklamsi mengalami fluktuasi dari tahun ke tahun. Hasil studi pendahuluan yang dilakukan dengan cara wawancara pada bulan Juli 2018, dari 12 ibu hamil terdapat $8(66,6 \%)$ ibu hamil yang mengalami preeklamsia dan diduga tidak memeriksakan kehamilannya secara teratur.

Diagnosis dini preeklampsia yang merupakan pendahuluan dari eklampsia perlu dilaksanakan untuk menurunkan angka kematian ibu dan anak. Preeklampsia merupakan suatu sindrom yang ditandai dengan hipertensi disertai proteinuria pada trimester kedua kehamilan atau pada usia kehamilan lebih dari 20 minggu. Meskipun dalam mendefinisikan preeklampsia selalu menimbulkan kontroversi karena penyebab pasti gangguan ini masih belum jelas, akan tetapi untuk tujuan klinis beberapa gejala yang dapat diterima, antara lain: gangguan hati (adanya mual dan nyeri dikuadran kanan atas), kegagalan koagulasi (trombositopenia dan gangguan pembekuan darah), gangguan neorologis (sakit kepala dan gangguan penglihatan), dan gangguan pertumbuhan janin penting dalam mengidentifikasi ibu dengan penyakit ini (Robson dan Jason, 2012).

Pemerintah Indonesia sedang berupaya keras dalam upaya penurunan kematian maternal, namun banyak hambatan yang bersifat multifaktorial. Karena penyebab preeklamsi belum diketahui secara pasti maka salah satu upaya guna mencegah terjadinya preeklampsia adalah menghindari factor risiko dan meminimalkan faktor determinan preeklamsi yang dapat terjadi. Upaya yang dilakukan tidak hanya dilaksanakan oleh tenaga kesehatan, namun perlu kerjasama dan keterlibatan dari klien, pemerintah dan tenaga kesehatan (Natiqotul, 2016)

Pemerintah Indonesia sudah mempunyai program sebagai upaya mengurangi angka kematian pada ibu hamil dan bayi, salah satunya denganAnte Natal Care (ANC). ANC merupakan upaya preventif program pelayanan kesehatan obstetrik untuk optimalisasi luaran maternal dan neonatal melalui serangkaian kegiatan pemantauan rutin selama kehamilan. Kunjungan ANC sebaiknya dilakukan 4 kali selama kehamilan yaitu K1(Kunjungan pertama) sampai K4 (Kunjungan empat). ANC yang dilakukan secara teratur dan rutin merupakan cara yang paling tepat dan penting untuk memonitor dan mendukung kesehatan ibu hamil normal dan mendeteksi dini ibu dengan kehamilan normal. Ibu hamil sebaiknya mengunjungi dokter sedini mungkin semenjak merasa dirinya hamil untuk mendapatkan pelayanan ANC (Prawirohardjo, 2011).

Pencegahan awal dari preeklamsi dapat dilakukan dengan cara melakukan kunjungan pemeriksaan kehamilan secara teratur. Pada saat kunjungan akan dilakukan anamnesa yang mana bisa mengetahui informasi terkait penyakit yang dialami misalnya dengan mengetahui tekanan darah sebelum hamil maka akan sangat membantu petugas kesehatan untuk membedakan antara hipertensi kronis dengan preeklamsi. Dengan pemeriksaan kehamilan secara teratur dan efektif dapat mencegah semakin berkembangnya preeklamsi menjadi eklamsi dan dapat mendeteksi dini diagnosa preeklamsi untuk mengurangi komplikasi yang akan terjadi akibat preeklamsi. Adapun tujuan melakukan pemeriksaan kehamilan secara teratur yaitu untuk mendeteksi apakah ada kenaikan tekanan darah saat kehamilan, 
screeningpreeklamsi serta pengambilan keputusan akan tindakan yang tepat untuk menyiapkan rujukan. Berdasarkan latar belakang tersebut peneliti tertarik untuk menganalisis pengaruh pemeriksaan kehamilan secara teratur terhadap kejadian preeklamsi.

\section{METODE PENELITIAN}

Penelitian ini merupakan penelitian analitik yang menjelaskan hubungan antar variabel dengan menggunakan alat bantu berupa kuesioner untuk mengukur setiap variabel yang diteliti. Rancang bangun penelitian ini adalah Retrospektif Study yang mana penelitian ini dilakukan dengan pengamatan terhadap perisiwa - peristiwa yang telah terjadi dan bertujuan untuk mencari faktor yang berhubungan dengan penyebab.Penelitian ini dilakukan di Kabupaten Probolinggo. Populasi pada penelitian ini adalah semua ibu hamil pada tahun 2018. Teknik Sampling dalam penelitian ini menggunakan Purposive Sampling. Sampel: Sebagian ibu hamil yaitu sebanyak 200. Pengumpulan data dengan menggunakan kuesioner dan wawancara serta dianalisa dengan Univariat dan Bivariat dengan Chi-Square.

\section{HASIL DAN PEMBAHASAN}

\section{Analisis Univariat}

\section{Distribusi Kejadian Preeklamsi}

Tabel 1. Distribusi Kejadian Preeklamsi di Kabupaten Probolinggo Tahun 2018

\begin{tabular}{ccc}
\hline Variabel & Frekuensi & Persentase \% \\
\hline Preeklamsi & 100 & 50 \\
Tidak Preeklamsi & 100 & 50 \\
\hline TOTAL & $\mathbf{2 0 0}$ & $\mathbf{1 0 0}$ \\
\hline
\end{tabular}

Berdasarkan tabel 1 menunjukkan bahwa sebagian ibu hamil (50\%) mengalami preeklamsi.

Tabel 2. Distribusi Keteraturan Pemeriksaan Kehamilan di Kabupaten Probolinggo Tahun 2018

\begin{tabular}{lcc}
\hline \multicolumn{1}{c}{ Variabel } & Frekuensi & Persentase $\%$ \\
\hline Tidak teratur & 115 & 57,5 \\
Teratur & 85 & 42,5 \\
\hline TOTAL & $\mathbf{2 0 0}$ & $\mathbf{1 0 0}$ \\
\hline
\end{tabular}

Berdasarkan tabel 2 menunjukkan bahwa sebagian besar ibu hamil melakukan pemeriksaan kehamilan secara tidak teratur yaitu $57,5 \%$ dari total jumlah partisipan sebanyak 200 orang.

\section{Analisis Bivariat}

Tabel 3. Pengaruh Pemeriksaan Kehamilan yang berkualitas terhadap kejadian Preeklamsi tahun 2018

\begin{tabular}{|c|c|c|c|c|c|c|c|}
\hline \multicolumn{8}{|c|}{ Kejadian Preeklamsi } \\
\hline \multirow{2}{*}{ Variabel } & \multicolumn{2}{|c|}{ Preeklamsi } & \multicolumn{2}{|c|}{ Tidak Preeklamsi } & \multicolumn{2}{|c|}{ Total } & \multirow{2}{*}{ P value } \\
\hline & n & $\%$ & $\mathbf{n}$ & $\%$ & $\mathbf{n}$ & $\%$ & \\
\hline Tidak teratur & 68 & 68 & 47 & 47 & 115 & 57,5 & \\
\hline Teratur & 32 & 32 & 53 & 53 & 85 & 42,5 & 0,003 \\
\hline Total & 100 & 100 & 100 & 100 & 200 & 100 & \\
\hline
\end{tabular}

Berdasarkan dari analisis bivariat menunjukkan bahwa dari 115 partisipan yang tidak memeriksakan kehamilannya secara tidak teratur terdapat 68 partisipan yang mengalami preeklamsi, sedangkan dari 85 partisipan yang memeriksakan kehamilannya secara teratur terdapat 32 mengalami preeklamsi.Hasil uji statistik diperoleh nilai $\mathrm{p}=0,003$ sehingga dapat diartikan bahwa ada pengaruh antara pemeriksaan kehamilan secara teratur terhadap kejadian preeklamsi. 


\section{PEMBAHASAN}

Hasil penelitian ini menunjukkan ada pengaruh pemeriksaan kehamilan secara teratur terhadap kejadian preeklamsi.Pemeriksaan kehamilan atau asuhan Antenatal Care (ANC) merupakan suatu proses pemeriksaan yang dilakukan sejak masa kehamilan sampai saat proses persalinan dan pemeriksaan masa kehamilan ini dilakukan untuk mengawasi dan memonitor kesehatan ibu dan bayi sehingga proses kehamilan hingga persalinannya dapat berjalan sesuai yang diharapkan (Rukiyah, dkk. 2009).

Untuk menghindari gangguan pada kehamilan, ibu hamil diwajibkan melakukan pemeriksaan Antenatal Care (ANC) yang baik dan teratur. Antenatal Care merupakan suatu pemeriksaan kehamilan yang memiliki beberapa tujuan, yaitu: Memantau kemajuan kehamilan, memastikan kesejahteraan ibu dan tumbuh kembang janin. Meningkatkan dan mempertahankan kesehatan fisik, mental, serta social ibu dan bayi. Menemukan secara dini adanya masalah/ gangguan dan kemungkinan komplikasi yang terjadi selama masa kehamilan. Mempersiapkan kehamilan dan persalinan dengan selamat baik ibu maupun bayi dengan trauma seminimal mungkin. Mempersiapkan ibu agar masa nifas dan pemberian ASI eksklusif berjalan normal.

Mempersiapkan ibu dan keluarga dapat berperan dengan baik dalam memelihara bayi agar dapat tumbuh dan berkembang secara normal. Menurut standart asuhan kehamilan kunjungan Antenatal Care (ANC) minimal dilaksanakan 4 kali, yaitu: satu kali pada trimester I (usia kehamilan 0-13 minggu), satu kali pada trimester II (usia kehamilan14-27 minggu), dan dua kali pada trimester III (usia kehamilan 28-40 minggu) (Sulistyawati, 2012).

Pelayanan ANC yang rutin mencakup minimal 4 kali kunjungan di tiap trimester (minimal 1 kali pada trimester I, 1 kali pada trimester II, dan 2 kali pada trimester III umur kehamilan) dilakukan pemeriksaan $7 \mathrm{~T}$ berupa pemeriksaan fisik dan mental ibu hamil yakni tinggi badan dan timbang berat badan, ukur tekanan darah, pengukuran tinggi fundus uteri, pemberian imunisasi TT, pemberian tablet zat besi (minimal 90 tablet) selama kehamilan, tes penyakit menular seksual (VDRL), dan temu wicara atau konseling (Wati, 2011).
Pelayanan ANC berpengaruh pada kejadian preeklampsia dapat terjadi karena masih belum maksimalnya pelayanan ANC yang diberikan kepada ibu hamil. Hal ini sejalan dengan hasil penelitian yang menunjukkan adanya hubungan antara pelayanan ANC dengan kejadian preeclampsia. Sehingga ibu hamil yang tidak rutin memeriksakan kehamilannya mempunyai risiko 9,6 kali untuk mengalami preeclampsia disbanding dengan ibu hamil yang rutin ANC (Isnanda et al., 2014).

Banyak berbagai faktor yang menyebabkan masyarakat tidak melakukan pemeriksaan secara teratur misalnya masyarakat belum mengetahui tentang manfaat pemeriksaan kehamilan, factor demograf sebagai alas an masyarakat khususnya ibu hamil tidak melakukan pemeriksaan kehamilan, jarak tempuh ke sarana pelayanan kesehatan yang sangat jauh, petugas kesehatan yang sering tidak berada di tempat pelayanan, sehingga masih ada persalinan yang ditolong oleh dukun. Demikian juga masih ditemukan ibu hamil yang tinggal di daerah perkotaan belum melakukan pemeriksaan kehamilan secara teratur.

\section{KESIMPULAN}

Sebagian besar ibu hamil yang mengalami preeklamsidalam masa kehamilannya yaitu sebanyak 50\% dan sebagian besar dari mereka juga tidak memeriksakan kehamilannya secara teratur. Jadi setelah dianalisis didapatkan hasil 0,003 yang artinya ada pengaruh antara pemeriksaan kehamilan secara teratur terhadap kejadian preeklamsi.

\section{SARAN}

Memberikan pendidikan kesehatan yang berkaitan kepada masyarakat khususnya calon ibu maupun ibu hamil untuk mempersiapkan kehamilannya dan menjaga kehamilannya baik proses pemeriksaan kehamilannya maupun menjaga kesehatan sendiri selama kehamilannya,serta lebih menekankan kepada petugas kesehatan untuk lebih mengoptimalkan pelayanan ANC kepada seluruh ibu hamil, Program Perencanaan Persalinan Dan Pencegahan Komplikasi (P4K), deteksi dini resiko tinggi, ANC terpadu, kelas ibu hamil. 


\section{REFERENSI}

Isnanda, E. P., Noor, M. S., Musafaah, M.(2014).Hubungan Pelayanan Antenatal Care(Anc) Dengan Kejadian Preeklampsia Ibu Hamil Di RSUD Ulin Banjarmasin. Jurnal Publikasi Kesehatan Masyarakat Indonesia.

Natiqotul F, Kodiyah, Masturoh (2016). Determinan Maternal Kejadian Preeklampsia (Studi Kasus Di Kabupaten Tegal, Jawa Tengah) : Jurnal Keperawatan Soedirman. Vol. 11 No.1 : 53 - 61

Prawirohardjo, S. (2011). Ilmu Kebidanan. Jakarta: Yayasan Bina Pustaka Sarwono Prawirohardjo.

Raghupathy R. (2013). Cytokines as Key Playersinthe Pathophysiology of Preeclampsia. Journal Medical Principles and Practice, 22 (23), 8-19.
Robson, Jason W, Elizabeth S. (2012). Patologi pada kehamilan. Jakarta: EGC.

Rukiyah, dkk.(2009). Asuhan Kebidanan I (Kehamilan). Cetakan Pertama. Penerbit CV. Trans Info Media

Sulistyawati. (2012). Asuhan Kebidanan pada Masa Kehamilan. Jakarta: Salemba Medika

Wati SH. (2011). Hubungan Pengetahuan Ibu Hamil Trimester III tentang Antenatal Care Terhadap Pelaksanaan K4. Skripsi.Medan: Universitas Sumatera Utara. 